J Ästhet Chir 2010 - 3:66-66

DOI 10.1007/s12631-010-0078-z

Online publiziert: 8. April 2010

(c) Springer-Verlag 2010

\author{
H.-G. Bull \\ St. Josefshospital Uerdingen, Krefeld
}

\title{
Ohrrekonstruktion und Ohranlegeplastik
}

Sehr geehrte Frau Kollegin, Sehr geehrter Herr Kollege,

Das Journal für ästhetische Chirurgie widmet sich in dieser Ausgabe dem Schwerpunktthema der Ohrrekonstruktion und -anlegeplastik. Dabei wird nicht nur die angeblich "so einfache" Ohrmuschelanlegeplastik vorgestellt, sondern auch die autologe Rekonstruktion schwerer Fehlbildungen und Defekte der Ohrmuschel sowie die Ohrrekonstruktion mit alloplastischen Gerüsten. Namhafte Autoren handeln dieses Thema kritisch und auf neuestem wissenschaftlichem Stand ab.

Daneben möchte ich Sie bereits jetzt auf den diesjährigen Jahreskongress der Gesellschaft für Ästhetische Chirurgie Deutschland hinweisen, der unter der Jahrespräsidentschaft von Prof. Kaufmann, Dr. Lampe und Dr. Wolters vom 21.10.2010 bis zum 23.10.2010 in Frankfurt am Main stattfinden wird. Einladungen zu diesem Kongress sind bereits erfolgt.

\section{( D Der Jahreskongress der GÄCD findet vom 21. bis 23.10.2010 in Frankfurt am Main statt}

Da die ästhetische Chirurgie besonders bei den Weiterbildungsassistenten bereits auf großes Interesse stößt und im Klinikalltag für Fortbildungen auf diesem Gebiet oft wenig Zeit bleibt, wollen wir auf dem diesjährigen Kongress der GÄCD versuchen, eine Fortbildungslücke zu schließen und etwa 100 jüngeren Kollegen die Möglichkeit geben, mit Karten zu deutlich er- mäßigten Preisen an der Tagung teilzunehmen. Zu Beginn des Kongresses wird am Donnerstagnachmittag für diese Teilnehmer ein „Assistentenforum“ durchgeführt werden. Wir hoffen, dass mit dieser Neuerung eine Fortbildungslücke geschlossen wird.

Ich wünsche den Mitgliedern der Gesellschaft und allen Leserinnen und Lesern viel Spaß bei der Lektüre dieser Ausgabe und eine glückliche und erfolgreiche Frühlings- und Sommerzeit 2010.

Ihr



Prof. Dr. Dr. H.-G. Bull

\section{Korrespondenzadresse}

Prof. Dr. Dr. H.-G. Bull

St. Josefshospital Uerdingen Kurfürstenstr. 69, 47829 Krefeld bull.mkg@stjosef.de 